\title{
Modeling surface roughness of point robot laser hardening, with emphasis on the surface
}

\author{
Matej Babič \\ Faculty of Information studies \\ Ljubljanska cesta $31 a$ \\ 8000 Novo mesto, Slovenia \\ babicster@gmail.com
}

\begin{abstract}
The topic of Machine Learning is so popular that it is not only the future trend, but also the money tide. Machine learning technique and intelligent system methods are very popular in mechanical engineering. Robot laser surface hardening is one of the most promising techniques for surface modification of the microstructure of a material to improve wear and corrosion resistance. For predicting the surface roughness of the hardened specimens, the support vector machine and multiple regression is used. The aim of this paper is to present modeling roughness of point robot laser hardened specimens with different parameters of robot laser cell.
\end{abstract}

Keywords: modeling, surface roughness, robot, laser, hardening.

\section{Introduction}

The research and construction of machine learning (Char, Shah, Magnus, 2018) is a special algorithm (rather than a specific algorithm) that allows the computer to learnfrom the data to make predictions. Therefore, machine learning is not a specific al gorithm, but a collective term for manya lgorithms. Machine learning includes ma ny different a lgorithms. Deep learning (Rolnick, Tegmark, 2018) is one of them. Other methods include decision trees, clustering, Bayes, etc.

Deep learning is inspired by the structure and function of the brain, which is the interconnection of many neurons. Artificial Neural Network (ANN) (Varun Kumar, Ajith, Václav, 2017) is an algorithm that simulates the biological structure of the brain. Whether it is machine learning or deep learning, it belongs to the category of artificial intelligence (Al).
Las er hardening (Babič, 2018) is rapid hea ting and self-excited cooling. It does not require furnace insulation and coolant hardening. It is a pollutionfree and environmentally friendly heat treatment process that can easily perform uniform hardening on the surface of large molds. Because the laser heating speed is fast, the heat-affected zone is small, and the surface scanning hea ting and hardening, that is, the local heating and hardening are instantaneous, the deformation of the processed mold is s mall. Due to the small divergence angle of the laser beam, it has good directivityand can accuratelylocal quench the mold surface through the light guide system. The depth of the hardened layer of laser surface hardening is generally $0.3 \sim 1.5 \mathrm{~mm}$ Industrial robots ensure the proximity of laser beams to components. The laser light source of the laser is operated by an industrial robot. An attached swivel-tilt table for 
workpiece positi oning a lmost completely ensures the proximity of the laser beam to the surface of the component. The industrial robot can be supplemented with linear coordinate axes when needed.

The aim of this paper is to present modeling roughness of point robot laser hardened specimens with different parameters of robot laser cell.

\section{Material preparation and method}

Our study was limited to tool steel of DIN standard 1.7225. The chemical composition of the material was 0.38 to $0.45 \%$ C, $0.4 \%$ maximum $\mathrm{Si}, 0.6-0.9 \%$ $\mathrm{Mn}, 0.025 \%$ maximum $\mathrm{P}, 0.035 \%$ maximum $\mathrm{S}$, and $0.15-0.3 \%$ Mo. Firstly, we point robot laser hardened specimens with different temperature $T \in[850$, $1300]^{\circ} \mathrm{C}$ and power $\mathrm{P} \in[1000,1500] \mathrm{W}$. After point robot laser hardening (Fig. 1), specimens were polished and etched. Detailed characterization of their microstructure (Fig. 2) surface modifications was conducted using a JEOLJSM-7600F field emission scanning electron microscope (SEM). We used the program ImageJ (available from the National Institute of Health, USA) to analyze these pictures.

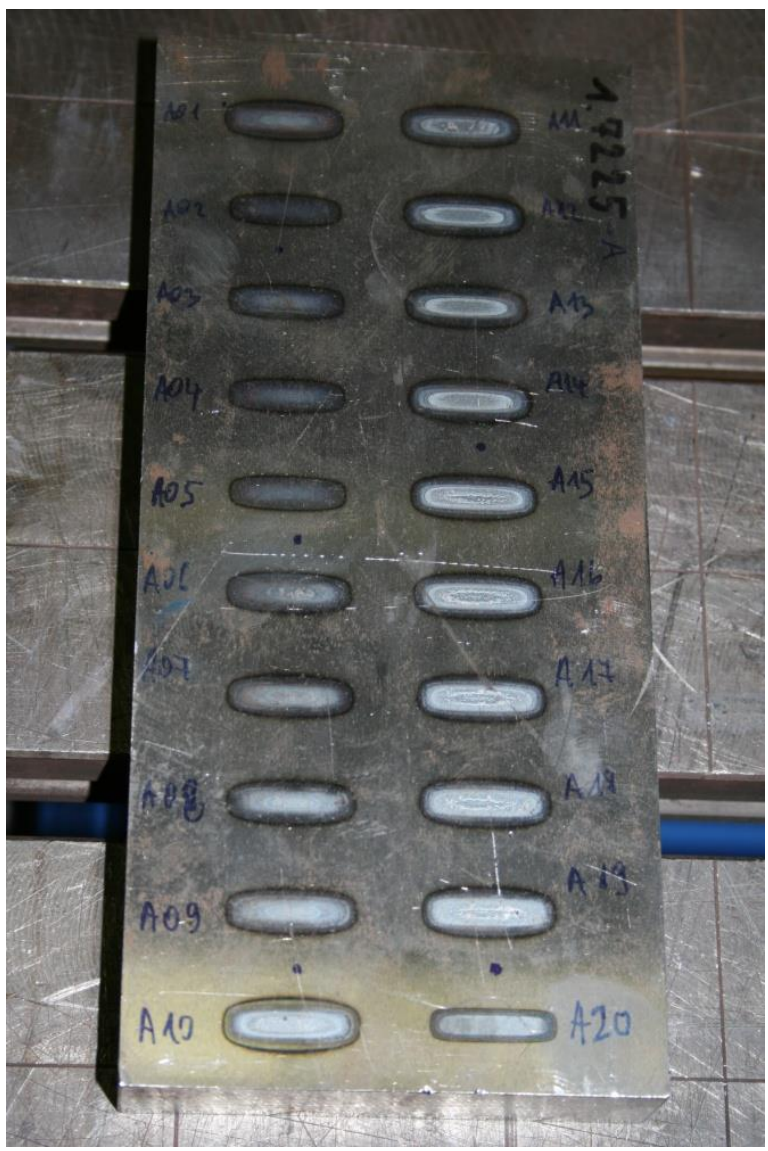

Figure 1. Point robot laser hardened specimen with different parameters of robot laser cell

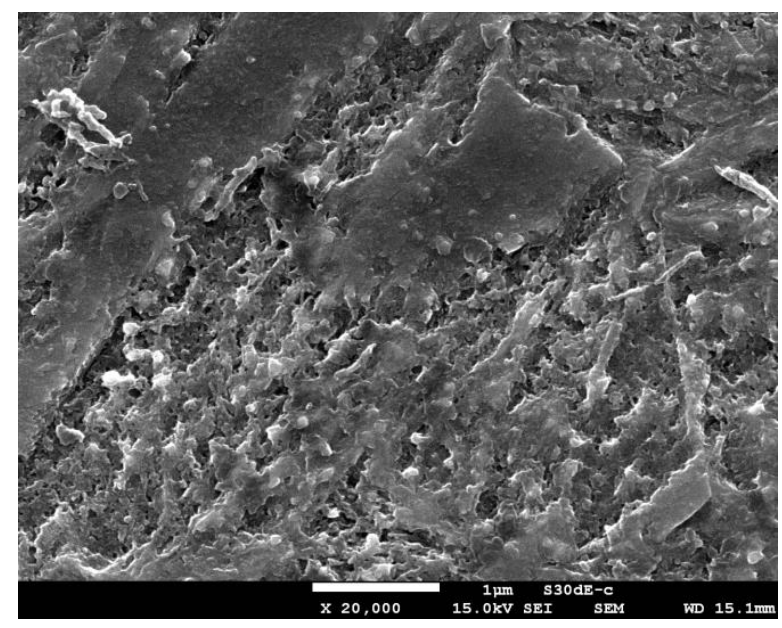

Figure 2. Microstructure (SEM) of point robot laser hardened specimen

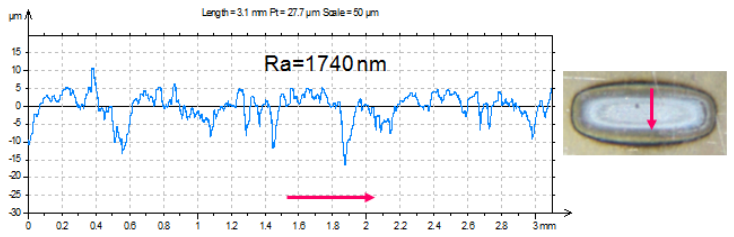

Figure 3. Roughness of point robot laser hardened specimen

On these specimens, (Fig. 3) the roughness of the robot-laser-hardening were measured. A profilometer (available from the Jožef Stefan Institute of Ljubljana) was used to measure the surface roughness parameter Ra (arithmetic mean deviation of the roughness profile) and hardness of the robot-laser-hardened specimens.

For a nalysis of the results, we used an intelligent system methods (Cuevas, Díaz, Camarena, 2021), namely multiple regression (Srinivasan, Murugasan, 2021) and support vector machine (Xiong, Mo, Yan, 2021).

Multiple linear regression is an extension of simple linear regression, which studies the quantitative dependence between a dependent variable and multiple independent variables. Multiple linear regression uses a regression equation to describe the dependence of a dependent variable and multiple independent variables, referred to as multiple regression. Figure 4 represent example of multiple regression.

The mathematical model of multiple linear regression is:

$$
Y=b_{0}+b_{1} X_{1}+b_{2} X_{2}+\ldots+b_{m} X_{m}+\varepsilon,
$$

where, for $\mathrm{i}=\mathrm{n}$ observations:

$Y$ is dependent variable, $X_{i}$ is explanatory variables, 
$b_{0}$ is y-intercept (constant term),

$b_{m}$ is slope coefficients for ea ch explanatory variable $\epsilon$ is the model's error term (also knownas the residuals).

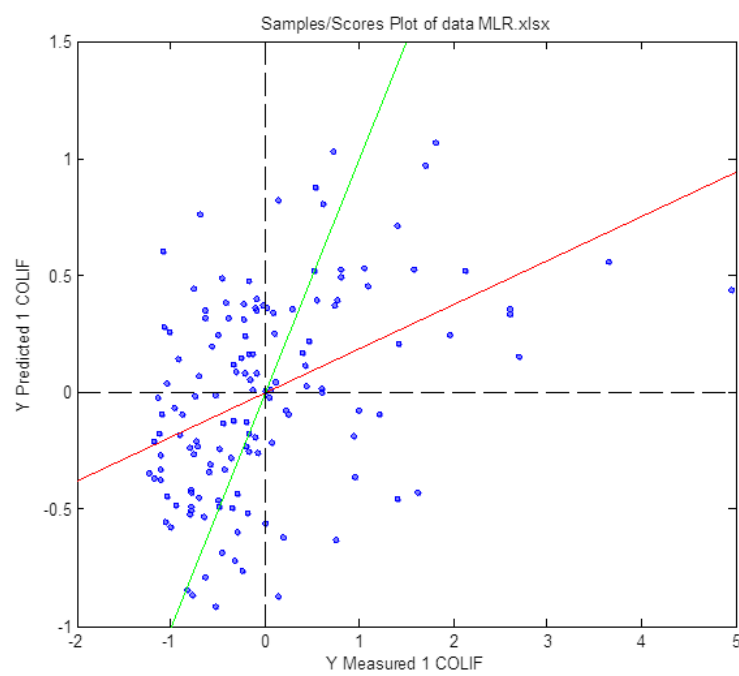

Figure 4. Example of multiple regression

Almost all machine learning courses will talk about a very classic algorithm called a support vector machine. It is very easy to apply the support vector machine to practical problems. Support Vector Machine(SVM) is a machine learning model based on statistical learning theory. I thas rel ative adva ntages for small samples, nonlinea rities, high dimensionality and local minimum points. This concept was actually put forward by mathematicians Vapnic and Chervonenkis as earlyas the 1960s and 1990s, and established this set of statistical learning theory. In addition to good results in text classification, image classification, and protein classification in medicine, it al so has a wide range of applications in industry due to its a dvantages of fast calculation speed and low space cost. Figure 5 represent example of support vector machine.

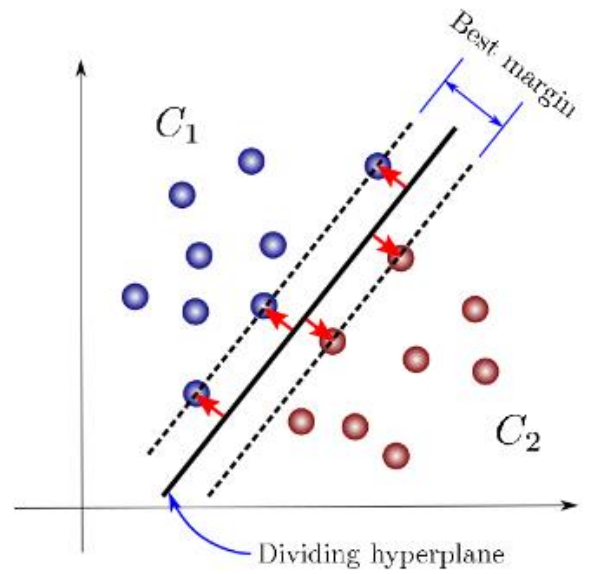

Figure 5. Example of support vector machine

\section{Results and discussion}

Table 1 represent parameters of robot laser hardened specimens. Column S presents notation of point robot laser hardened specimens with different power and temperature. Column X1 represents tempera ture of point robot laser hardening. Column $\mathrm{X} 2$ represents power of point robot laser hardening. The last column represents roughness of point robot laserhardening. The higher roughness has specimen P12. P12 is point robot laser hardened with para meter $900{ }^{\circ} \mathrm{C}$ and $1500 \mathrm{~W}$. Minimal roughness has specimen P7. P7 is point robot laser hardened with parameter $1150{ }^{\circ} \mathrm{C}$ and $1000 \mathrm{~W}$.

Table 2 represent measured and predicted roughness of point robot laser hardened specimens. In column S notation of specimens are presented. Second column represents meas ured data. The next column represents predicted data with support vector machine P SVM and the last one represents predicted data with multiple regression $P M R$.

We use v-SVM Type with regression cost (C) 1,00. Optimization parameters, we use 100 iteration li mit and numerical tolerance 0,001. We use Kernel $(\mathrm{g} \times \mathrm{x} \times \mathrm{y}+0.13)^{3}$ and $\mathrm{g}$ was auto.

Prediction with multiple regression has $83 \%$ precision. Prediction with support vector machine has $73 \%$ precision. Model of multiple regression is presented by equation (1).

\begin{tabular}{|c|c|c|c|}
\hline $\mathrm{S}$ & $\mathrm{X} 1\left(^{\circ} \mathrm{C}\right)$ & $\mathrm{X} 2(\mathrm{~mm} / \mathrm{s})$ & $\mathrm{Y}(\mathrm{nm})$ \\
\hline $\mathrm{P} 1$ & 850 & 1000 & 1156 \\
\hline $\mathrm{P} 2$ & 900 & 1000 & 892 \\
\hline $\mathrm{P} 3$ & 950 & 1000 & 1336 \\
\hline $\mathrm{P} 4$ & 1000 & 1000 & 1008 \\
\hline $\mathrm{P} 5$ & 1050 & 1000 & 835 \\
\hline $\mathrm{P} 6$ & 1100 & 1000 & 933 \\
\hline $\mathrm{P} 7$ & 1150 & 1000 & 760 \\
\hline $\mathrm{P} 8$ & 1200 & 1000 & 775 \\
\hline $\mathrm{P} 9$ & 1250 & 1000 & 799 \\
\hline $\mathrm{P} 10$ & 1300 & 1000 & 1346 \\
\hline $\mathrm{P} 11$ & 850 & 1500 & 1569 \\
\hline $\mathrm{P} 12$ & 900 & 1500 & 1740 \\
\hline $\mathrm{P} 13$ & 950 & 1500 & 1187 \\
\hline $\mathrm{P} 14$ & 1000 & 1500 & 1125 \\
\hline $\mathrm{P} 15$ & 1050 & 1500 & 1916 \\
\hline $\mathrm{P} 16$ & 1100 & 1500 & 1677 \\
\hline $\mathrm{P} 17$ & 1150 & 1500 & 1518 \\
\hline $\mathrm{P} 18$ & 1200 & 1500 & 1217 \\
\hline $\mathrm{P} 19$ & 1250 & 1500 & 1286 \\
\hline $\mathrm{P} 20$ & 1300 & 1500 & 1766 \\
\hline & & & \\
\hline
\end{tabular}

Table 1. Parameters of robot laser hardened specimens 


\begin{tabular}{|c|c|c|c|}
\hline S & $Y(n m)$ & $\begin{array}{c}\text { P SVM } \\
(n m)\end{array}$ & $\begin{array}{c}\text { P MR } \\
(\mathrm{nm})\end{array}$ \\
\hline P1 & 1156 & 892 & 1021 \\
\hline P2 & 892 & 1156 & 1013 \\
\hline P3 & 1336 & 1008 & 1005 \\
\hline P4 & 1008 & 1336 & 996 \\
\hline P5 & 835 & 1008 & 988 \\
\hline P6 & 933 & 835 & 980 \\
\hline P7 & 760 & 933 & 972 \\
\hline P8 & 775 & 799 & 963 \\
\hline P9 & 799 & 1346 & 955 \\
\hline P10 & 1346 & 799 & 947 \\
\hline P11 & 1569 & 1740 & 1537 \\
\hline P12 & 1740 & 1187 & 1529 \\
\hline P13 & 1187 & 1740 & 1521 \\
\hline P14 & 1125 & 1916 & 1512 \\
\hline P15 & 1916 & 1677 & 1504 \\
\hline P16 & 1677 & 1916 & 1496 \\
\hline P17 & 1518 & 1677 & 1488 \\
\hline P18 & 1217 & 1518 & 1480 \\
\hline P19 & 1286 & 1217 & 1471 \\
\hline P20 & 1766 & 1286 & 1463 \\
\hline
\end{tabular}

Table 2. Measured and predicted roughness of point robot laser hardened speceimens

$$
Y=-0.16406 X_{1}+1.0322 X_{2}+128.16515
$$

In process of robot laser hardening parts are not deformed. Laser hardening is clean, efficient, and does not require cooling media such as water or oil. The hardening hardness is higher than the conventional method, and the hardened layer has a fine structure and good toughness.

Intel ligent Sys tem is aiming at the strategic needs, focusingon the theoreticalchanges and application challenges brought about by future intelligent technologies, studying the theory, technical models and key algorithms of human-computer confrontation for intelligent decision-making, forming human-computer confrontation.

\section{Conclusion}

In this paper is presented modeling roughness of point robot laser hardened specimens with different parameters of robot laser cell. Two methods of intelligent system namely; support vector machine and multiple regression are presented to predict surface roughness of point robot laser hardened specimens, with emphasis on the surface. Prediction with multiple regression has better precision as support vector machine.

In the future research, several parameters of point robot laser cell and several machine learning methods can be used.

\section{References}

Char, D. S.; Shah, N. H.; Magnus, D. (2018). "Implementing Machine Learning in Health Care-Addressing Ethical Challenges". New England Journal of Medi cine. 378 (11): 981-983. doi:10.1056/nejmp1714229.

Rolnick, D., Tegmark, M. (2018). "The power of deeper networks for expressing natural functions". International Conference on Learning Representations. ICLR 2018.

Varun Kumar, O., Ajith, A., Václav, S. (2017). Metaheuristic design of feedforward neural networks: A review of two decades of research. Engineering Applications of Artificial Intelligence. 60: 97-116. arXiv:1705.05584.

Babič, M. (2018). New double cycle hybrid method of machine learning using laser heat treatment pattern recognition with the topological properties of a network. Lasers in engineering, ISSN 0898-1507, vol. 40, no. 1/3, str. 95-105.

Cuevas, E., Díaz, P., Camarena, O. (2021). Metaheuristic Computation: A Performance Perspective. Intelligent Systems Reference Library 195, ISBN 978-3-030-58099-5, pp. 1-269.

Srinivasan, K., Murugasan, R. (2021). Web-based GIS for live GV of land generation through utilitarian as sociation rule mining and multiple regression analysis for Chennai district. Concurr. Comput. Pract. Exp. 33(3).

Xiong, W., Mo, Y., Yan, C. (2021) Online State-ofHealth Estimation for Second-Use Lithium-Ion Batteries Based on Weighted Least Squares Support Vector Machine. IEEE Access 9: 18701881. 